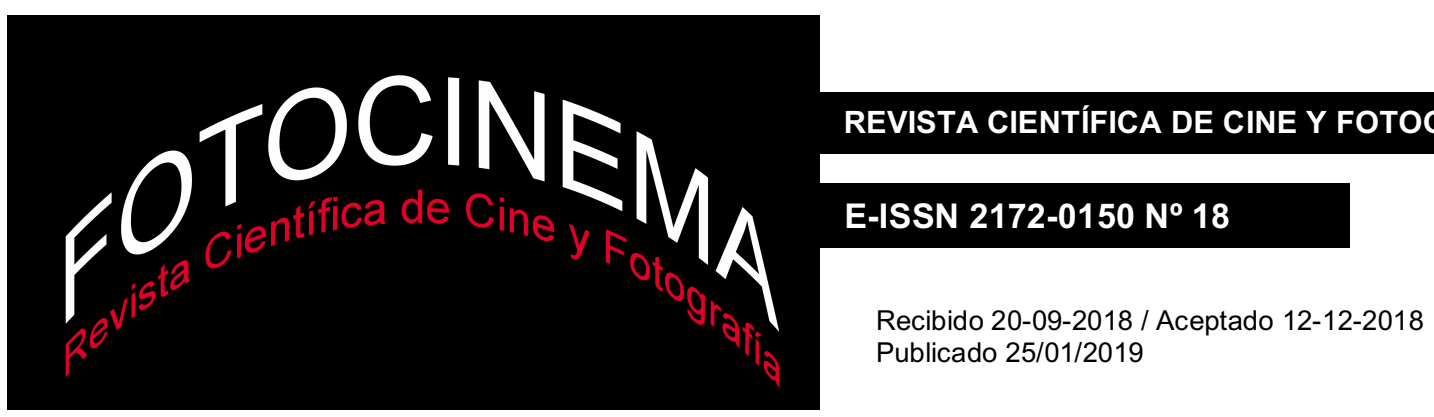

\title{
El trabajo de mesa en el audiovisual: la hermenéutica de la palabra/logos
}

\section{The Table Work in the Audiovisual Media: The Hermeneutics of the Word/Logos}

\section{Resumen:}

Emeterio Diez Puertas

Universidad Camilo José Cela, España https://orcid.org/o0oo-0002-2206-0480 ediez@ucjc.edu

Jorge Iván Suárez

Universidad del Atlántico, Colombia https://orcid.org/oooo-0001-5971-2684 jorgeisuarez@mail.uniatlantico.edu.co

El artículo tiene por tema el trabajo de mesa. Su objeto es describir, desde una aproximación hermeneútica, los elementos que componen dicha técnica y cómo afectan al proceso de transducción del texto escrito al audiovisual. Para ello se ha empleado la técnica cualitativa de la entrevista en profundidad, tanto directa (entrevistas a profesionales españoles) como indirecta (a través de libros de entrevistas). La hipótesis es que el trabajo de mesa se articula sobre el concepto logos y tres de sus significados: palabra, razón y pensamiento. Pero las dudas sobre en qué momento situar el trabajo de mesa, cuánto debe durar, en qué debe consistir o qué pasa con los casos especiales, a punta, más bien, a una conclusión que evidencia que hay una complicada interacción entre logos y praxis, la cual se resuelve con la razón poética.

\begin{abstract}
:
The theme of this article is the table work. It describes, from an hermeneutical framework, the elements that make up this technique and how they affect the process of transduction from the written text to the audiovisual. The methodology is based on the qualitative technique of the in-depth interviews, both direct (interviews with Spanish professionals) and indirect (through interview books). The hypothesis is that table work is articulated on the concept of logos in its triple meaning: word, reason and thought. But the doubts shown about when to place the table work, how long it should last, what it should consist of or what happens with the special cases, draw the conclusion that there is a complicated interaction between logos and praxis, which is solved with poetic reason.
\end{abstract}

Palabras clave:

Palabra; guion; trabajo de mesa; puesta en escena; transduccion; hermenéutica

Keywords:

Word; Script; Table work; Mise-en-scene; Transduction; Hermeneutics 
$\mathrm{Al}$ modo de la semilla se esconde la palabra. Como una raíz cuando germina que, todo lo más, alza la tierra levemente, mas revelándola como corteza [...] una corteza que ha de ser atravesada.

María Zambrano, Claros del bosque, p. 93

\section{Introducción}

Frederick Winslow Taylor es, a finales del siglo XIX, uno de los fundadores y primeros estudiosos de la organización científica del trabajo, de modo que la revolución industrial es tanto producto de nuevos inventos y de nuevas fuentes de energía como de la introducción de la división del trabajo, la parcelación de las tareas, la especialización profesional y demás soluciones organizativas destinadas a aumentar la productividad. De hecho, podemos considerar el cine como el invento que permite la transformación de un proceso artesanal de producción de historias representadas por actores, el del teatro, en otro modo que consigue la producción de esas historias de una forma industrial: fabril, maquinista, especializado, seriado, para su consumo en masa...

En realidad, desde mediados del siglo XVIII, el sistema de producción teatral, que podemos calificar de gremial, había caído en tal descuido, faltas y errores que surge todo un movimiento para reformarlo. Por ejemplo, el actor Konrad Ekhof establece una cadena de pasos previos a cualquier estreno teatral, como son el ensayo de la representación durante varios días y la lectura completa de la obra que se va a llevar a escena por parte del reparto, pues era práctica corriente que el actor se limitase a leer y memorizar exclusivamente su papel (citado por Chiarini, 1993, p. 25). De hecho, la aparición de la figura del director, de un especialista, en vez de hacer la puesta en escena el actor-empresario, forma parte del mismo proceso de reforma de un sistema que va dejando de ser gremial, que se contagia de taylorismo (como es el uso de la expresión "montaje"), que se inflama de "obrerismo" (y el pago de los ensayos pasa a ser una de las principales reivindicaciones de los actores), pero que tampoco puede ser industrial por su propia naturaleza de espectáculo en vivo.

En este sentido, teatro y cine entran en competencia y puede decirse que el segundo gana al primero, precisamente, por su más efectivo modo de producción. Ahora bien, más que la destrucción del aparato teatral, lo que se produce es un trasvase a la industria del cine de sus profesionales, sus salas, su repertorio, su normativa legal y, sí también, de los métodos de organización del trabajo que habían introducido los ilustrados. Un ejemplo son el concepto "puesta en escena" 
(montaje de una representación para la embocadura de un teatro o el objetivo de una cámara) y el tema que nos trae aquí: el "trabajo de mesa", "análisis de mesa" o "periodo de mesa”. En inglés, se usan las expresiones: table-read, table work y read-through. Con ellas se denomina la fase de trabajo, en el proceso de los ensayos, en el que el equipo artístico y técnico proceden a una lectura y análisis de la obra a representar o del guion a rodar, normalmente alrededor de una mesa, con el fin de entender el sentido profundo del texto, resolver dudas sobre el mismo y definir y dar coherencia a la puesta en escena que ha concebido el director. Este trabajo puede implicar asistir a cursos y conferencias o ver y leer material adicional. El trabajo de mesa, en otras palabras, está ligado a la figura del director y a los procesos artísticos que le competen, si bien es cierto que son los actores quienes más han codificado esta práctica, tanto en la preparación profesional como en la legislación laboral, como si el periodo de mesa solo estuviese ligado a la dirección de actores. ${ }^{1}$

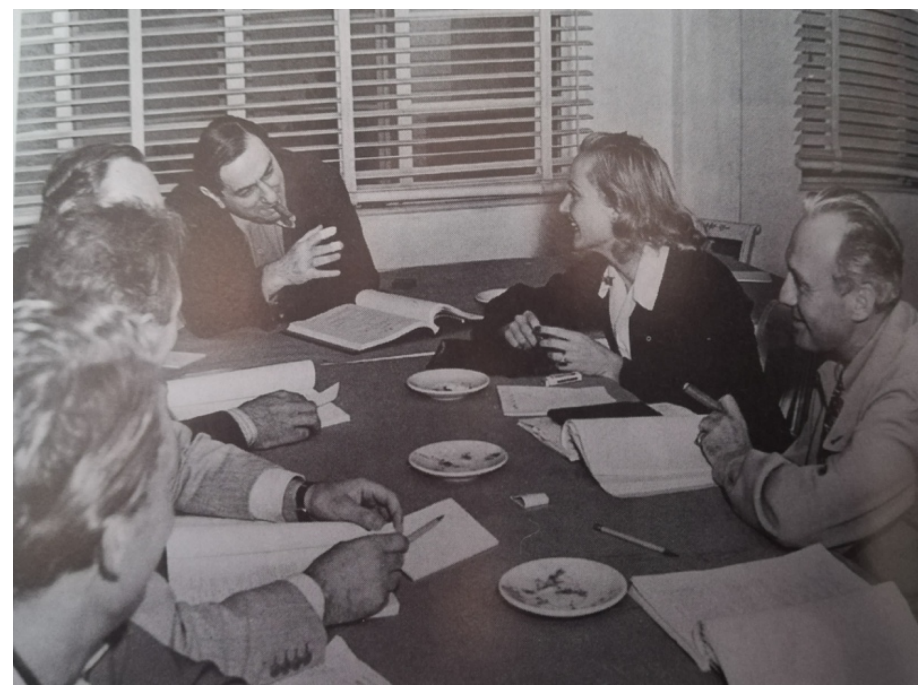

F1. Lectura inicial del guion de Ser o no ser (To be or not to be, Ernst Lubitsch, 1942). (C) Academy of Motion Pictures Arts and Sciencies.

\footnotetext{
1 En efecto, el III Convenio colectivo estatal regulador de las relaciones laborales entre los productores de obras audiovisuales y los actores, de mayo de 2016, aunque no menciona específicamente el trabajo de mesa, sí establece que en el contrato deben figurar los días de ensayo que se prevé realizar y su fecha. Además, señala expresamente que "queda excluida la obligatoriedad de realizar ensayos gratuitos". El salario mínimo es de entre 40 y 50 euros, según categorías. Por otro lado, la proliferación de programas tipo "making of" y las subidas a redes de videos rodados durante el proceso de preproducción (entrevistas, audiciones, lecturas previas...) con el fin de adelantar o de proveer la promoción de la película o de la serie explica que el convenio también considere que se pueda grabar el ensayo "a efectos de publicidad", pero sin que la emisión final supere los cinco minutos. Además de los vídeos recogidos en estas páginas, en You Tube puede verse parte del trabajo de mesa realizado en muchas producciones, por ejemplo, en la película Beauty and the Beast (Bill Condon, 2017) (https://www.youtube.com/watch?v=VqieWP-tx5Q) y la serie de The Office (NBC, 2005-2013) (https://www.youtube.com/watch?v=hAUW6cgBcko).
} 
La necesidad de este trabajo surge del hecho de que el teatro y el cine son artes mediadas. ${ }^{2}$ Entre el guion y el público, hay una segunda creación, unos artistas y técnicos ejecutantes que deben de hacer de negociadores entre el escritor y el espectador y son claves en la inteligibilidad del texto. Precisamente, la crítica literaria ha acuñado el concepto transducción para aquellas formas de comunicación artística en las que entre autor, obra y receptor se sitúa una cuarta instancia, un intermediario, un ejecutante, que comunica la obra, pero transformada (Dolezel, 1986). Aquí vamos a entender la transducción como el proceso creativo por el cual las palabras del guion se convierten en signos fílmicos por un equipo de profesionales bajo la batuta de un director. En este sentido, la puesta en escena constituye un proceso hermenéutico. Forma parte de la filosofía de la interpretación, del proceso de transmisión de significados.

El objetivo de estas páginas, en concreto, es estudiar cómo se hace esa transducción en las películas y series durante el proceso llamado trabajo de mesa. La causa que da origen a la investigación tiene que ver con la pregunta: ¿Un estudiante que quiere hacer series y películas debe aprender este proceso? ¿Y en qué consiste, qué dicen sobre él los libros publicados en español, qué explican sus profesores en las aulas, que verán en el mundo profesional cuando hagan sus prácticas? ¿Vale la pena aprender este proceso hermenéutico? Nuestra hipótesis es que el trabajo de mesa es un proceso ineludible que se articula sobre el concepto logos, en cuanto que moviliza tres de sus significados: palabra, razón y pensamiento. Esto es, el trabajo de mesa consiste en leer palabras (logos 1), en descifrarlas y analizarlas mediante la razón (logos 2) y en encontrar y pactar un sentido, una clave que haga posible la transducción (logos 3 ).

Para demostrar esta hipótesis se ha empleado la técnica cualitativa de la entrevista en profundidad, tanto directa como indirecta. En el primer caso, los criterios de selección de la muestra fueron no probabilísticos. Se buscaron 30 profesionales que sabíamos que hacían este trabajo por informaciones de colegas o búsqueda en internet. Solo una parte aceptó participar y la agenda de otros impidió completar el proceso. 3 Esto perjudicó la muestra en su componente internacional y, más en concreto, iberoamericano. Finalmente, se contactó o se

\footnotetext{
${ }^{2}$ No vamos a entrar en la controversia de si el teatro es literatura y el guion no, de si la palabra es la esencia en un medio, pero no en el otro, como sostienen algunos autores (Feldman, pp. 153161). ¿Las obras de teatro de David Mamet son literatura, pero sus guiones originales no? Tampoco estas páginas son un estudio sobre las relaciones personales y profesionales, anécdotas biográficas incluidas, que mantiene el director con el productor, el guionista, los actores u otros profesionales.

3 En 1996 Jacoste Quesada señalaba que, a diferencia de la televisión, en la industria española del cine los ensayos con los actores "ha sido durante mucho tiempo ignorada absolutamente" (1996, p. 146). Los profesionales elegidos para nuestra muestra, por el contrario, son defensores de este proceso.
} 
envió un cuestionario a 15 profesionales, dos de ellos de Colombia y otro de Ecuador. En cualquier caso, se buscó cierta representatividad. En primer lugar, por sectores: cine (10) y televisión (5). También se cumplieron unas cuotas profesionales: actores (2), directores y/o guionistas (8), productores (4) y escenógrafos (1), la mayoría de los cuales eran también docentes. En tercer lugar, se buscó una cuota mínima por sexo: hombres (10) y mujeres (5). Las entrevistas formaban parte de un trabajo mayor sobre cómo se aborda la palabra en el proceso del ensayo y, en general, sobre el trabajo con el texto en el teatro y el audiovisual. Las preguntas relacionadas con el trabajo de mesa obedecían a una cadena estructurada que buscaba establecer dónde, cuándo, quiénes hacen qué durante el proceso de trabajo de mesa por qué y para qué. La información se obtuvo entre diciembre de 2016 y junio de 2018. Las entrevistas fueron transcritas y preparadas por uno de los semilleros del Grupo de Investigación Teatro, Espacio e Interactividad (TEI) de la Facultad de Bellas Artes de la Universidad del Atlántico de Barranquilla (Colombia). En cuanto a la información indirecta, se recurrió a libros de entrevistas que recogen la experiencia de ciertos profesionales, vídeos sobre el Cómo se hizo y manuales del oficio (Lumet, 1999; Miralles, 2000; Edgar-Hunt, 2015).

\section{Producción y planificación de las "lecturas"}

Las reuniones, pruebas y ensayos son una parte fundamental de la fase de preproducción y no solo prácticamente todas se hacen "con el guion en la mano" sino que, varias de ellas, consisten en leer el "papel”. Por ejemplo, durante las audiciones, los actores hacen una lectura en frío, es decir, leen por primera vez un fragmento del guion, aunque lo normal es que se haya pasado al actor el texto sobre el que va a realizar la prueba (Barr, 2002, p. 169).

De hecho, el proceso de encarnación de la palabra comienza durante el casting, que conlleva pruebas distintas, además de que el actor lea su papel, como estar en situación delante de la cámara o hacer pruebas de vestuario. El productor Santiago García de Leaniz Caprile hace dos apreciaciones interesantes relativas a los muchos huecos abiertos que dejan las palabras:

Yo siempre digo una cosa: el casting no es sólo el look, es la voz, es el sonido de la voz. El 60\% de un actor es la voz. Y me interesa mucho cómo son capaces de coger un texto fresco, nuevo, que a lo mejor ha memorizado o no, cómo son capaces de matizarlo. Entonces, decir un "Te quiero" de una manera o de otra, es que cambia totalmente. Por eso trabajo mucho el sonido directo y, a veces, hasta límites insospechados, aunque luego pueda ir en detrimento de mi propio tiempo de rodaje. 
Por otro lado, en el casting, es fundamental contraponer los personajes. Tú a lo mejor dices: "Él es el personaje que yo quiero. Es el que quiero que haga de científico". Pero ¿quién es su rival? ¿Quién es su antagonista? A veces ocurre que se hacen castings erróneos porque no se han puesto los dos juntos. (Santiago García de Leaniz Caprile, comunicación personal, 13-12-2016).

Por otro lado, lo normal es que, antes de los ensayos, el director se encuentre con cada uno de los miembros de la producción por separado. Javier Fadón, actor, dice: "Yo soy partidario de que haya un trabajo previo antes. Quiero que el director me cuente un poco su punto de vista, su visión estética, dónde quiere ir, qué margen me da, precisamente, para ir a ese trabajo de mesa con algo y tener claro hasta dónde puedo llegar" (comunicación personal, 8-11-2017). Es más, en algún caso, estas reuniones son el centro de la preproducción. Dice el director Miguel Santesmases: "Hay directores que sientan en una mesa muy larga a todos sus actores y en un día hacen la lectura de todo el guion. Yo nunca he hecho eso. No me gusta trabajar así. Yo prefiero preparar a cada actor por separado" (comunicación personal, 13-12-2016). Mike Figgis, un director que viene del teatro, opina que, aunque los actores demandan ensayar, en realidad, no les gusta ensayar. Les parece como estar en el colegio o tener que ponerse a preparar un examen. Por eso, suele resolver sus dudas en conversaciones en una habitación del hotel o reuniendo a un par de actores en una comida y hablar (citado por Lowenstein, 2001, pp. 181-182). En el caso de Sin muertos no hay carnaval (2016), un drama social sobre la ocupación de tierras por desplazados en la ciudad de Guayaquil, las reuniones de Sebastián Cordero con los responsables de arte y fotografía fueron en este sentido:

Una cuestión importante con el director de arte era cómo se quería ver Guayaquil, ¿en época húmeda o seca? Porque la ciudad es muy diferente. Yo tenía fotos del lugar donde íbamos a rodar las ocupaciones que daban un estilo de favelas, de lugar de miseria. Eran de la época seca. Pero yo no quería contar esto. Quería contar que la gente quiere quedarse en esas ocupaciones porque está verde, porque hay al lado un bosque muy lindo, porque tienen su huerto, porque se está bien. Son casas de caña, de pobre, pero en un sitio digno. Esto era una capa sutil, pero muy importante para definir la película que yo quería. Con el director de fotografía, hablamos de la luz en Guayaquil. Es bastante difícil de tratar al estar en el ecuador. Hay un clima muy cambiante y un sol cenital que no ayuda, pero hay unas mañanas espectaculares. Él se pasó mucho tiempo estudiando cómo trabajar con esta luz. (Sebastián Cordero, comunicación personal, 22-6-2018).

Tras estas reuniones y la firma de los contratos, comienzan los ensayos. Pueden durar entre dos y cuatro semanas. El productor Santiago García de Leaniz Caprile dice: "se presupuestan unas tres o cuatro semanas de lectura de guion y de ensayo. Ahí entran ya las pruebas de vestuario, de maquillaje... Entonces empieza a correr el dinero. Te estoy hablando de una película media" (comunicación personal, 1312-2016). Sidney Lumet, en concreto, planificaba un periodo de ensayos de dos semanas, tres en el caso de Veredicto final (The Verdict, 1982) y cuatro en Larga 
jornada hacia la noche (Long Day's Journey Into Night, 1962). De este periodo de ensayo, Lumet destinaba al trabajo de mesa dos o tres jornadas. En cuanto al dónde, el trabajo de mesa se hace en la productora o en un local contratado por la misma, pero, con equipos pequeños, puede convocarse, por ejemplo, en la casa del director.

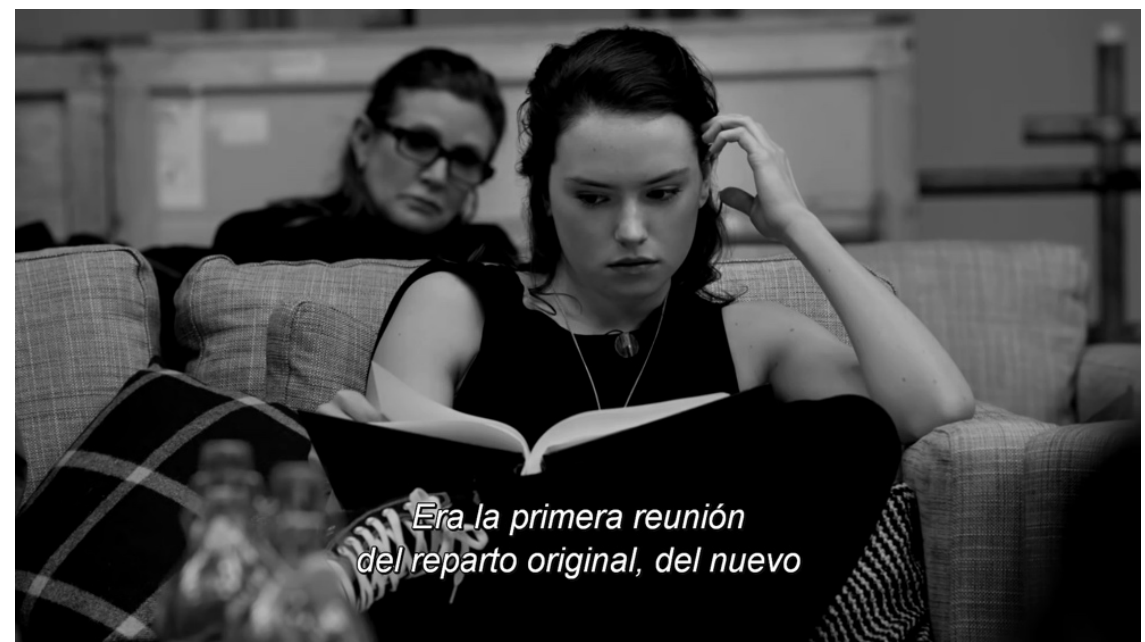

Video 1. Grupo reunido para la lectura del guion de Star Wars. Episodio VII El Despertar de la Fuerza (Star Wars. Episode VII: The Force Awakens, J.J. Abrams, 2016).

https://www.youtube.com/watch?v=aEbOHghGTUo\&feature=youtu.be (c) You Tube.

En el audiovisual, el trabajo de mesa, en realidad, es doble. Hay un trabajo de mesa con los actores en el proceso de ensayos y un trabajo de mesa con los jefes de equipo en el proceso de preparación del rodaje. En este sentido, la industria distingue entre la lectura artística y la lectura técnica del guion. La primera es para leer el texto y analizarlo en cuanto a desarrollo de los personajes, sentido del texto, clave de género, etc. (véase Vídeo 1). La lectura técnica es con los jefes de departamento y busca coordinar los equipos técnicos y conseguir una preproducción lo más completa posible, es decir, que anticipe los problemas en la posterior fase de rodaje. Rara vez entra en cuestiones de contenido, bien porque no interesan o se han resuelto en reuniones previas. En el audiovisual, en la lectura artística, están el director, su ayudante, el guionista, los actores, en ocasiones, el director de producción, y, en las series de televisión, los coordinadores de guion. Para Mi Gran Noche (Alex de la Iglesia, 2015), en la primera lectura del guion había 21 personas. La lectura técnica se hace con el director, su ayudante y todos los jefes de equipo: vestuario, maquillaje, fotografía, sonido, dirección artística, etc. Dice Julio Medem:

Durante el rodaje estoy fundamentalmente volcado con los actores y la cámara. Con el resto del equipo hay que estar sobre todo antes de empezar a rodar, y es en ese momento en el que hay que contarlo todo. En las lecturas de guion, que ocupan varios días $\mathrm{y}$, por otro lado, en las reuniones con los responsables de departamentos y algunos ayudantes. (Recogido de Angulo y Rebordinos, 2005, p. 239). 
En la ficción para televisión, donde la palabra "serie" indica tanto continuidad por capítulos o episodios como producción en cadena, los tiempos son algo distintos. Incluso se ruedan varios capítulos al mismo tiempo. En Cuéntame (TVE, 2001- en antena), por ejemplo, hay entre 3 y 4 semanas de preproducción y 9 días (jornadas) de filmación. Las lecturas se hacen los miércoles, dos semanas antes del rodaje. Dice Ignacio del Moral:

A veces, cuando arranca la serie, hay muchos guiones escritos, se hace una lectura artística de 5, 6 o 7 capítulos de seguido y luego a rodar. Al final, inmersos ya en el proceso de grabaciones, el tiempo va disminuyendo. Las últimas lecturas son muy aceleradas. Hay mucha diferencia con la tranquilidad que se vive al principio. Cuanto más avanza el proceso de grabación, más complicado se va haciendo todo. (Ignacio del Moral, comunicación personal, 12-1-2017).

En cuanto a la lectura técnica, se hace una semana o diez días antes del rodaje y esa lectura puede tardar 3, 4 o 5 horas. "Es muy larga y muy pesada, dice Ignacio del Moral, porque es escena a escena. Ahí no se leen los diálogos, sino las acotaciones, porque es técnico. Cada uno añade sus notas y el director toma decisiones y se acuerdan cambios" (comunicación personal, 12-1-2017).

El trabajo de mesa termina cuando comienza la puesta en pie, proceso del que hablaremos más adelante. Es más, tras los ensayos puede haber otros procedimientos, ya en la fase de producción, que también consisten en leer y analizar el texto. En especial, se recurre a la mesa italiana. Esta es una lectura de la secuencia que inmediatamente se va a rodar para estudiar y repasar el texto. No hay que olvidar que, además del periodo de ensayos, se ensaya en el set antes del rodaje para probar tomas, movimientos, luces, sonido... En la serie Cuéntame, por ejemplo, la actriz Alicia Hermida se ocupaba de las lecturas a la italiana. Repasaba la secuencia a rodar para decir bien el texto, entender qué es lo que se quería contar, hallar los puntos fuertes de la secuencia y definir el tono. "A veces, decía en una entrevista, algún actor me dice que no entiende el texto y se lo leo. No hago nada más que respetar la puntuación. Es que hoy en día no se tiene cultura del texto" (recogido por Rosado, 2010). También en este momento preparaba a los actores más jóvenes, sobre todo, para impedir que sobreactuasen.

\section{El proceso y sus objetivos}

Como en el teatro, el trabajo de mesa persigue cuatro grandes metas: 1) comenzar a crear equipo; 2) que el director presente su propuesta de puesta en escena y pacte su sentido; 3) leer y analizar el guion y ver si requiere cambios o bien hay que facilitar referencias y documentación añadida; y, sobre todo, 4) que el director responda en todo momento a cuantas preguntas surjan sobre estas 
cuestiones. En este sentido, el trabajo de mesa suele ser una ceremonia que sigue tres pasos: la intervención del director, la primera lectura colectiva de la obra y el análisis del texto. Claro que situaciones especiales, como trabajar con niños o que los actores necesiten cierta formación, pueden implicar ciertos cambios en el proceso o que se sumen otras actividades antes, durante o después.

\subsection{La unidad de forma y contenido}

El trabajo de mesa, sea la lectura artística o la técnica, comienza con una disertación del director. Se presenta a sí mismo, si fuese preciso, y a todos los miembros del equipo. A continuación, transmite su lectura del guion, qué quiere contar: su logos (aquí entendido como el sentido, la forma y contenido profundo del relato). "Es superimportante, dice Sebastián Cordero, alinearnos todos. Asegurarse que todos estamos haciendo la misma película. Una película es un proceso creativo de un grupo grande, un pequeño ejército, y si no se tiene claro lo que estamos haciendo, uno puede enfrentarse a muchos problemas" (comunicación personal, 22-6-2018). En efecto, como señala Umberto Eco, el texto artístico es un texto abierto y esta característica es en sí un valor y un obstáculo. Permite actualizar un texto clásico o hacer un remake, pero se puede caer en la sobreinterpretación, es decir, que el director ponga por delante una lectura forzada del guion o bien puede que cada profesional vaya por su lado, lo que es compatible con decir que puntos de vista distintos suelen enriquecer el resultado, darle más complejidad. De hecho, el director evita comentar demasiado su propuesta. Dice Julio Medem: "yo no debo contarlo todo desde el principio, porque si no, ya sabéis cómo son estas cosas, te acaban diciendo, 'Vale. Lo que tú quieras'. Y no es exactamente así como hay que trabajar en equipo" (recogido de Angulo y Rebordinos, 2005, p. 239).

El director apoya su lectura en el cuaderno de dirección, el guion técnico o en las notas y comentarios que ha escrito en el propio guion literario. También puede llegar con documentación: libros, fotos, música, dibujos, etc. El director Miguel Santesmases, que como hemos indicado prefiere reuniones por separado, dice: "Mi cuaderno de dirección es un desglose por secuencia. Tengo una especie de mecanismo de trabajo qué tiene que ver con el efecto plástico que busco en la escena, pero también con los errores que debo evitar" (comunicación personal, 13-12-2016). Pero no se trata de imponer las ideas del cuaderno sino de, precisamente, ensayar si funciona. Anthony Minghella, que viene del teatro, dice: 
El aspecto más importante de la producción de una película es la unidad de estilo, que todo el mundo esté haciendo la misma película. Así que siempre intento estar todo el tiempo posible con los actores antes del rodaje. Y no solo con los actores, también pido al director de fotografía que se pase por los ensayos y hable con ellos de la película. A mí me parece que la información que se comparte nunca es demasiada." (Recogido de Lowenstein, 2001, p. 425).

Sobre lo que significa la búsqueda de una compleja unidad de sentido, dice el productor Juan Pablo Tamayo: "Para mí es fundamental que todo el mundo tenga muy claro qué película vamos a hacer, que todo el mundo sepa que esto es un drama, que todo el mundo sepa que esto es acción, que todo el mundo sepa que esto es humor" (comunicación personal, 7-8-2017). Santiago García de Leaniz Caprile expresa lo mismo con otras palabras: "Estamos haciendo una sola mirada. Pero que cuarenta, cincuenta personas, miremos todos en la misma dirección es muy complicado. Es cuestión de generosidad. Es entrega" (comunicación personal, 13-12-2016).

\subsection{La primera lectura}

A continuación, se pasa a la primera lectura. En el caso de la lectura artística, en el cine, rara vez se pide al actor que vaya con el texto memorizado. Lo normal es que acuda con un estudio y análisis de su personaje. En Flores de otro mundo (Icíar Bollaín, 1999), Luis Tosar se fue varias semanas a vivir a un pueblo para aprender las labores propias de un hombre del campo. Esta primera lectura suele hacerse sin interrupciones, de un tirón y es una lectura fría, esto es, como si se leyese la guía telefónica, sin apenas intenciones, sin tono, sin cuerpo, sin proyección de voz, más atenta al contenido del texto que a su carga emocional. Dice Javier Fadón: "No puedes dar intenciones sobre lo que todavía no hay acuerdo ni has escuchado. Sin tener datos suficientes, estas cerrando la creatividad un poco" (comunicación personal, 8-11-2017). Jean Renoir dice, en efecto, que debe ser una lectura fría, pues de lo contrario se puede caer en el cliché, algo preconcebido, algo que ya se ha visto en pantalla. Jean Renoir, por cierto, es otro de los decididos partidarios de los ensayos y del trabajo de mesa (véase el Vídeo 2). Lo hace por influjo de dos grandes actores de teatro que trabajan con él: Michel Simon y Louis Jouvet. De ellos aprende el proceso. Se basa en la idea de que la creación artística es centrípeta antes de hacerse centrífuga. 4

\footnotetext{
4 Denomina a esta forma de trabajar "método italiano", por lo que puede que, en su caso, hubiese más imbricación entre mesa y puesta en pie o bien hacía mesas italianas sucesivas.
} 


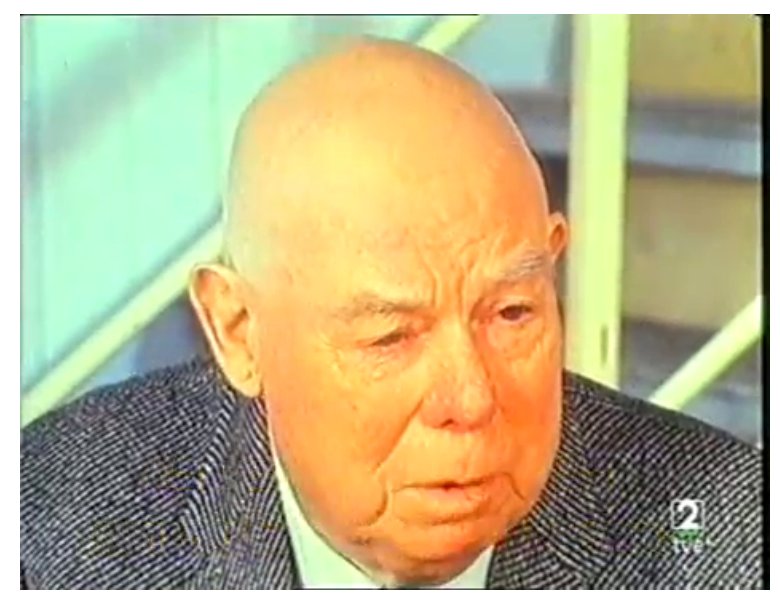

Video 2. En 1968 Jean Renoir rueda con la actriz Gisèle Braunberger un documental en el que puede verse su técnica de trabajo de mesa. https://www.youtube.com/watch?v=JGp2btfp24\&feature=youtu.be (C) You Tube.

En sus memorias dice:

Consiste básicamente en reunir alrededor de una mesa a los actores de la escena que se ensaya, y hacerles leer el texto, prohibiéndoles toda expresión. Esta lectura, para ser fructuosa, debe ser tan plana como la de la guía de teléfonos. Prácticamente todo actor concienzudo aprende su papel de este modo y se prohíbe cualquier reacción antes de haber explorado las posibilidades de cada frase, de cada palabra, de cada gesto. Los actores que dan en seguida una forma a la interpretación de un papel tienen todas las posibilidades de caer en el cliché. Cada parte de una obra de teatro o de una película puede ser una creación original, y el trabajo hecho deprisa no permite salirse de caminos trillados. Tal actriz debe interpretar el papel de una madre que se encuentra ante el cadáver de su hijo. Es muy posible que el modo de expresar su dolor esté copiado de algo ya visto. Los gritos y los llantos recordarán los gritos y los llantos de los que ella misma u otras actrices se hayan servido ya. Por eso nos reunimos aquí, los actores y el director, imponiéndonos la obligación de leer el texto dos, tres, veinte veces si es necesario. De pronto, en la lectura monótona, el director descubre un destello. iYa está! Partiendo de ahí, el comediante tiene probabilidades de llegar a una interpretación original del papel. Es algo mágico y rara vez falla. (Renoir, 2011, págs. 148-150).

En efecto, en esta primera lectura se trata de que todos se escuchen, de oír juntos la obra, de que cada actor encuentre en las palabras del guion la conexión que existe entre él y su personaje. La actriz Carla Calparsoro dice:

Esa primera lectura es mágica. Empiezas a escuchar a los otros personajes y no sólo a estar pendiente de lo tuyo. Entonces te pones en un lugar más imaginativo y distanciado. Porque cuando estás ensayando estás muy pendiente, no sé, del cuerpo, de las marcas... En la lectura no tienes movimiento ni ninguna obligación. Tienes cierta libertad para escuchar. Es un momento bueno para plantearte cosas que igual antes no te habías planteado dentro de lo que es el conjunto. (Carla Calparsoro, comunicación personal, 14-12-2016).

\section{3•3. El análisis textual}

Tras esta primera lectura, se abre una sesión de corrección de erratas tipográficas, de preguntas y de debate. Para salir airoso es muy importante la preparación previa del director, una preparación que, en realidad, alimenta todo el proceso de 
producción. "Yo creo, dice Miguel Santesmases, que es muy importante tener respuestas, ideas de fondo que puedes usar para explicar algo a un actor en cualquier momento o que le puedes decir al director de fotografía, o al director artístico" (comunicación personal, 13-12-2016).

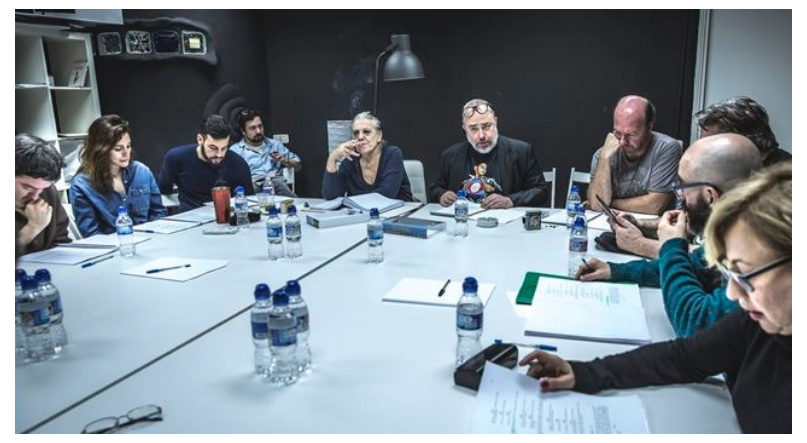

F2. Lectura de guion en El bar (Alex de la Iglesia, 2017). (C) Productora Nadie es perfecto

A continuación, se procede a una segunda lectura, ya en profundidad, escena por escena, y en la que se efectúa lo que se llama el análisis del texto. "El actor, dice Sebastián Cordero, tiene que entender y creerse cada acción de su personaje. Por qué se hace cada cosa y se dice cada cosa. Para que justamente, luego pueda ser natural" (comunicación personal, 22-6-2018). Es el aspecto duro y central del trabajo de mesa. Dice Lumet:

Lo normal es que los dos o tres primeros días nos sentemos alrededor de una mesa, $\mathrm{y}$ hablemos del guion. En primer lugar leemos el guion de corrido, y luego empleamos los dos días siguientes en desbrozar sus componentes. Lo primero que dejamos establecido es, por supuesto, el tema. Luego nos metemos en cada personaje, en cada escena, en cada palabra.

[...] La repetición es connatural a la realización cinematográfica. De modo que uno tiene que buscar elementos sustitutivos, "pautas", capaces de estimular las emociones que compensa la pérdida de instinto. De eso hablamos durante los dos días de intercambio de ideas. En otras palabras, empezamos a utilizar la técnica. (Lumet, 1999, pp. 69-70).

Precisamente, en esta tercera fase, el principal problema es encontrar una técnica o sistema de análisis del guion compartido, un marco teórico de referencia, un vocabulario (estado de ánimo, arco de trasformación, clímax...) entendible por todos. En efecto, la falta de un léxico técnico establecido, que es lo que permite a los médicos comunicarse mientras operan a un paciente y a los abogados pleitear ante un juez, suele ser un gran obstáculo en el proceso de transducción, sobre todo, porque parte de la profesión desdeña la terminología, usa palabras desusadas o viene de escuelas distintas. Desde luego, el análisis literario y la terminología académica al uso apenas sirve de marco conceptual. Tampoco ningún director de cine nos habló del sistema de análisis más extendido en el 
teatro: el análisis activo, desmenuzado por Osipovna Knébel en El último Stanislavski. Es un método que se apoya en la premisa de que las palabras, su semántica, su sintaxis, su prosodia, son el alimento del actor en cuanto que constituyen la fuente de imágenes y sensaciones.

\subsection{La lectura técnica}

En la lectura técnica, que puede superponerse con la anterior (así hace Gracia Querejeta), el procedimiento es el siguiente: el ayudante de dirección va leyendo el guion secuencia por secuencia, el director va explicando cómo va a rodarla y el equipo anota lo que le corresponda y pregunta, de modo que cualquier duda para el momento del rodaje se aclara. Es una lectura minuciosa, casi tediosa en la que cada departamento quiere resolver los retos de cada secuencia. Como señala Enrique Urbizu, con los actores el director puede permitirse ser evasivo, dejar que exploren por sí mismos, mientras que aquí el nivel de concreción es muy alto (comunicación personal, 12-9-2017). Por otro lado, a diferencia de la lectura artística, aquí el productor tiene más protagonismo y rara vez los jefes de equipo plantean preguntas sobre el sentido profundo del filme, cuál es su mensaje, qué simboliza esto a aquello, cuál es el arco de las escenas, etc. Incluso, como es una lectura puramente de producción, en ocasiones, ni se leen los diálogos. No obstante, esto está cambiando y en los casos con mejores prácticas, hay un verdadero trabajo de mesa. Dice el productor Juan Pablo Tamayo:

En Operación E [2012], de Miguel Cortuois Paternina, con guion de Antonio Onetti, llegamos todos con una copia del guion previamente leído con algunas preguntas anotadas por la página de atrás. Lo que hacemos es que nos repartimos las voces. Usualmente el director hace del narrador, lee las acotaciones. Luego cada quién hace un personaje. Leemos una escena "Interior. Salón. Día”, por ejemplo. "María y Pedro están sentados a la mesa". Cuando terminamos la escena, se hacen todas las preguntas. Nos podemos demorar una hora, dos horas, pero exijo que todo el mundo haga todas las preguntas. Además, las pongo en un tablero. Se puede hablar e interrumpir y ninguna pregunta es estúpida, lo que se les ocurra. (Juan Pablo Tamayo, comunicación personal, 7-8-2017).

\subsection{El caso de las series}

En Cuéntame, la primera lectura se hace con la presencia del director, el reparto principal, el guionista que ha escrito el capítulo y el coordinador de guiones. Se trabaja con el guion literario y también es una lectura de seguido, aunque, como solo se convoca a los actores principales y estos llevan años haciendo el mismo papel, no es una lectura fría. Dice Ignacio del Moral: 
En esa lectura se discute bastante y se hacen observaciones de cosas muy concretas sobre las escenas, los personajes, los diálogos... “¿Esto se entiende o se no entiende?” Los directores piensan en cómo visualizar. Entonces le explicas lo que habías pensado. Permite que todos estén mucho más familiarizados, que los actores estén más conformes. Redunda, en general, para bien porque se homogenizan criterios. Crea un clima favorable y ayuda a tener confianza, sobre todo, cuando ha gustado el guion. Cuando una serie pasa por dificultades, la culpa se focaliza con frecuencia en el guion. Entonces, si tú consigues que las lecturas artísticas vayan bien, el equipo sabe que el guion no es el responsable de los problemas porque ya se examinó en su momento. (Ignacio del Moral, comunicación personal, 12-1-2017).

Verónica Fernández, por su parte, señala:

En las lecturas en Cuéntame, recuerdo que había dos personas que decían cosas siempre muy interesantes. Una era María Galiana. Por su experiencia, por su formación y, claro, por su edad. Decía cosas muy interesantes de época o cosas que ella había vivido y que eran muy enriquecedoras. La otra persona era Alicia Hermida que, al mismo tiempo, hacía de "coach" de los actores y entonces ella trataba siempre de ir más allá del texto, por si luego tenía que ayudar a un actor. (Verónica Fernández, comunicación personal, 18-12-2016).

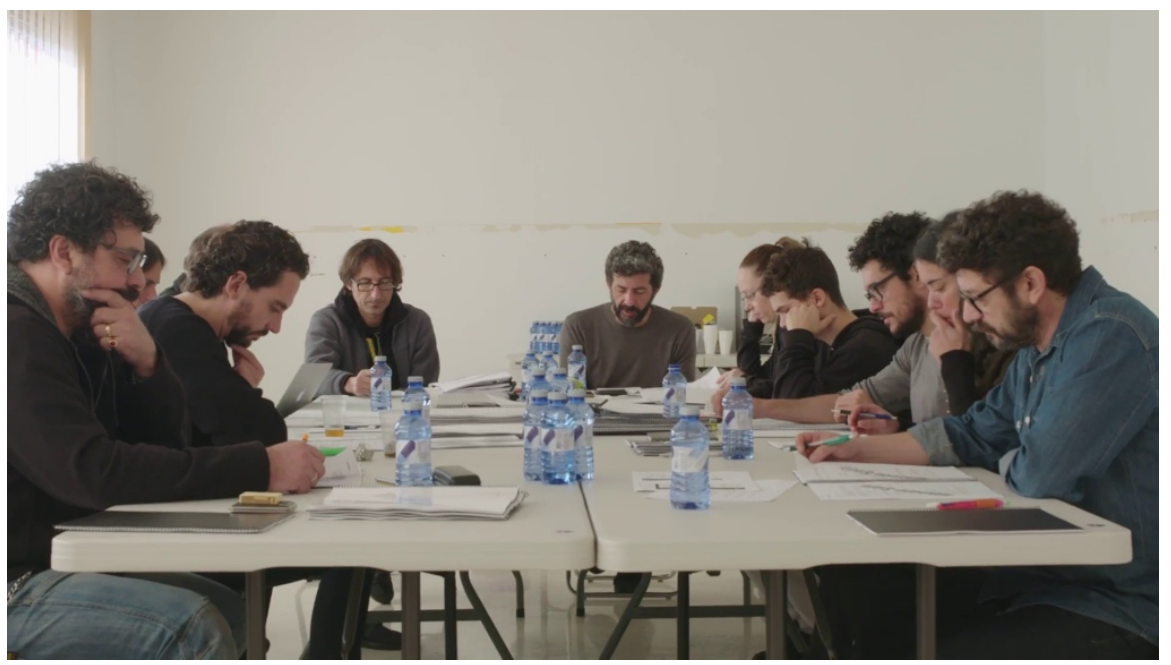

Video 3. Trabajo de mesa en La peste (Moviestar, 2018) https://www.youtube.com/watch?v=opv2e6dzLjc\&feature=youtu.be (C) You Tube

\subsection{Los cambios en el guion}

Una cuestión importante es si en el proceso de trabajo de mesa se debe modificar el guion. Casi todos los profesionales, incluido el guionista, entienden que sí. "Yo sigo corrigiendo el guion hasta el día de rodaje”, dice Sebastián Cordero. La página perdona mucho, cosas (localizaciones, vestuario, acciones, frases...) que, cuando empiezas la producción muchas veces ves que no funcionan" (comunicación personal, 22-6-2018). En realidad, se admite que se puede corregir el texto, pero no de forma sustancial o para hacerlo más cómodo al actor, y a ser posible, se busca que los cambios sean realizados por los guionistas y antes de cerrar el presupuesto o sin que le afecten de forma sustancial. Improvisado es 
no presupuestado. Puerto Collado, por su parte, considera que el texto que se lee en la lectura técnica debería ser definitivo, de lo contrario, habría imprevistos. ¿Cómo pedir en el rodaje una lámpara tipo Art Nouveau si en la lectura era una lámpara Bauhaus? Enrique Urbizu dice que, si es necesario se cambia, "pero con mucho, mucho cuidado. No por sistema” (comunicación personal, 12-9-2017). Lumet señala lo siguiente:

Al mismo tiempo, consideramos si hace falta reescribir algo. Empezamos a darnos cuenta de si falta algún elemento de transición, en un personaje o en la trama, si se transmite con claridad toda la información necesaria, si la película es demasiado larga o el diálogo rancio. Si hay mucho por hacer, es probable que el escritor desaparezca unos días [a reescribir]. Las modificaciones menores pueden manejarse bien en el propio sitio donde ensayamos. (Lumet, 1999, pp. 70).

De existir un momento de reescritura importante de la película no es en la mesa de ensayos sino más bien en la mesa de montaje. Dice Santiago García de Leaniz Caprile:

En la lectura del guion se cuenta todo, pero en imagen, una vez rodado, descubres que a veces sobra. Te das cuenta de que es demasiada información, que en una secuencia estamos diciendo lo mismo que dijimos ya en la secuencia tres. Lo descubres en el montaje. Otras veces ruedo una secuencia -y no se lo voy a decir a nadie-, que posiblemente no monte. Pero la tengo que rodar para darme el privilegio de poder quitarla. Montar también es renunciar, pero tener la posibilidad de poder renunciar. (Santiago García de Leaniz Caprile, comunicación personal, 13-12-2016).

En el caso de Cuéntame, con su ritmo de producción en serie, Ignacio del Moral dice respecto a los cambios de guion en la lectura artística:

En ocasiones, para los guionistas esta lectura es un poco tensa. Depende de los momentos de estrés o cansancio de los que participa, de cómo vayan las audiencias... A veces es un trago porque te sientes muy cuestionado. Alguna vez ha habido que reescribir guiones porque se han caído en esta lectura. La sensación de que no guste crea un clima desfavorable. Debo decir que, en los últimos años, la cosa ha estado más tranquila. Hay muchas ocasiones en que, cuando un actor te hace una observación, ves en seguida que tiene la razón. Tú tienes que tener mucha cintura. Saber aceptar muchas cosas para que, en el momento que te cuestionan el guion, sepas que es por algo. No por inflexibilidad o ego. Tienes que demostrar respeto y así ellos hacen el intento de valorar también tu propuesta. Lo que está o no está puesto en el guion a esas alturas es por algo. Hay cosas que están porque el director lo pidió, hay cosas que están porque el actor lo pidió, etc. En todo caso, de esta lectura sale una nueva versión, con más o menos cambios, que ya pasa a la lectura técnica. (Ignacio del Moral, comunicación personal, 12-1-2017).

Esta lectura técnica también puede implicar cambios que faciliten el ritmo de rodaje. Es, como dice Ignacio del Moral, la versión "recontradefinitiva”, pero que a veces no lo es porque incluso durante de la grabación pueden surgir imprevistos de toda índole. 


\subsection{Hacer equipo}

Finalmente, uno de los principales valores del trabajo de mesa es que comienza a crear equipo. "Es el momento donde se aprecia mejor quién necesita el apoyo de quién" (Gervasio Iglesias, comunicación personal, 13-9-2017). Es el lugar para poner "en común los problemas y las soluciones de todo el equipo" (Enrique Urbizu, comunicación personal, 12-9-2017). Ang Lee dice que "hay que pasar tiempo con los actores como sea" y, aunque para él los ensayos no tienen mucho sentido, cumplen esa misión (recogido por Lowenstein, 2001, p. 285). Lo mismo sostiene Barry Levinson, que sí es partidario de ensayar, pero no todo el guion de un tirón. Las lecturas, afirma, sirven para que unos se familiaricen con otros y para acabar con las inhibiciones que impiden decir lo que uno piensa (recogido por Lowenstein, 2001, p. 323). Jane Campion afirma que los ensayos sirven para aprender a conocer a los actores, hacer que confíen en ella como directora y aprender entre todos a respaldarse (recogido por Ciment, 2003, p. 420). La guionista Verónica Fernández, por su parte, recuerda que, en ocasiones, la primera lectura del capítulo de una serie se ha convocado como una especie de evento simbólico de hermandad:

En las series El síndrome de Ulises y en Seis hermanas hacíamos un evento del capítulo primero. Un evento es una reunión enorme en la que está todo el elenco y está también el autor. Se hace para vernos las caras, que los actores estén tranquilos y comenzar la relación profesional. En el cine, en la última película que yo estuve, se hizo una reunión justo un día antes del rodaje. Estaba el productor, el director, el guionista y el elenco completo. Se hizo una lectura completa y también se hizo como para decir empieza el rodaje mañana. (Verónica Fernández, comunicación personal, 18-12-2016).

\section{Los límites del logos}

Todos los involucrados en una filmación señalan que una buena preproducción (y en ella incluimos los ensayos con su periodo de mesa) abarata y acorta la filmación porque "resuelve dudas que ya no se plantearán durante el rodaje" (Enrique Urbizu, comunicación personal, 12-9-2017) y porque "evita muchos problemas que surgirían por no haber aclarado y prevenido el proceso de trabajo" (Puerto Collado, comunicación personal, 3-10-2017). El productor Gervasio Iglesias, por ejemplo, dice que "cuanto mejor preparada esté la película, mejor saldrá después en el rodaje que es la fase crítica y definitiva” (comunicación personal, 13-9-2017). Otro productor, Juan Pablo Tamayo, afirma: 
Yo procuro siempre hacer una preproducción muy larga, el tiempo que se tome, porque siempre digo: "Lo que no se prepara en la preproducción, fallará en el rodaje". Si va a ver cien problemas en el rodaje, que la preproducción te evite setenta. Que lo que ocurra en el rodaje, ya no sean imprevistos sino imponderables. Yo soy muy amigo de la planificación. A veces creo que me excedo un poco. Muchos directores me dicen que planeo demasiado, pero el dinero no es de ellos. (Juan Pablo Tamayo, comunicación personal, 7-8-2017).

Y el director Miguel Bardem señala:

Cuando empieza el rodaje, ya no hay tiempo para pensar. Hay que ejecutar y hacer lo establecido, lo que hay que rodar para cada día y cumplir el plan. Cada día de rodaje cuesta una fortuna, cualquier retraso es un chorro de dinero perdido. Por eso se dice que, cuanto más preparada esté una película, más difícil será que algo salga mal. En España, el tiempo de preparación no es el adecuado. (Miguel Bardem, comunicación personal, 11-10-2017).

Además, cuando los ensayos y la preproducción en general están bien hechos, se nota enseguida en la calidad de la película. Dice Santiago García de Leaniz Caprile: "Para el equipo es muy fascinante y bonito ver aquello que hicimos en la oficina, en la productora o donde sea, que todo aquello cuadra" (comunicación personal, 13-12-2016).

Sin embargo, el trabajo de mesa tiene varios peligros: encaja mal o debe replantearse con actores no profesionales, puede caer en un exceso de raciocinio y de especulación teórica, además de pasarse demasiada información, y es contraproducente estar demasiado tiempo sentados a la mesa. En efecto, en situaciones especiales, como trabajar con actores no profesionales o naturales, el trabajo de mesa y todos sus procesos con la palabra y la razón pueden resultar poco eficaces. El director colombiano Carlos Arbeláez procede así en estos casos:

$\mathrm{Si}$ al actor natural le impones aprender un libreto, lo dañas. Lo que hago es que empiezo a hacer improvisaciones con ellos en un sitio que no es el sitio de rodaje, por ejemplo, sobre ese pasado de ellos. Así ensayamos uno o dos meses. Yo grabo todos los ensayos. Me gusta ver los ensayos con ellos y luego volvemos a ensayar. Salen cosas chéveres que no están en el guion, pero que hay que tener en cuenta. Igual cuando ya vamos a hacer el rodaje, llevo los casetes o apuntes con cosas que ellos hicieron, con cosas que no están en el guion, pero me gustaría que hicieran. Los ensayos van aportando mucho al guion. Pero a los actores naturales si los ensayas mucho, los dañas. Si los ensayas poco, van como con dudas al rodaje. Uno tiene que dejarlos en el punto exacto. (Carlos Arbeláez, comunicación personal, 118-2017).

Respecto al exceso de intelectualismo, la productora Elena Manrique dice: "Yo personalmente soy muy partidaria de descontextualizar toda la conversación. Porque cuando intelectualizamos pueden verse vasos vacíos $\mathrm{y}$, si puedes decir lo mismo de forma más sencilla, pues bien. El lenguaje coloquial lo explica todo" (comunicación personal, 5-2-2017). Y en cuanto al tiempo en la mesa, Miguel Bardem asegura: "lo más importante con los actores es ensayar [poner en pie] todo lo que se pueda. Es mucho mejor que una lectura” (comunicación personal, 
11-10-2017). En el video 2, en el que puede verse a Jean Renoir ensayando con Gisèle Braunberger, cuando el director pide que el texto sea dicho ya con intención, la actriz siente la necesidad de ponerse en pie para encontrar la expresión. Renoir dice: "Me parece que ahora quiere levantarse". Ella, un poco cansada de estar atada a la mesa, responde: "Tengo ganas". Y Renoir acepta con un "Bueno" un poco contrariado. Luego, al ver el resultado, dice: "Creo que nos hemos levantado demasiado pronto". Pero la actriz necesita una y otra vez levantarse para poder seguir incorporando el texto. Por todas estas razones, algunos directores no hacen trabajo de mesa como tal, reducen sus procesos (casi lo limitan a la lectura) o proponen una mayor integración entre trabajo de mesa y puesta en pie. En lugar de procesos sucesivos, se propone un ir y venir de la mesa a la puesta en pie. Lumet, por ejemplo, tras varios días de puesta en pie, solía volver a realizar una lectura de corrido de todo el guion, a la que invitaba al director de fotografía y al productor, y también el último día del periodo de ensayos hacía una o dos lecturas completas.

\section{La dialéctica con la puesta en pie}

Aunque el tema del artículo es el trabajo de mesa, su valoración no puede hacerse si contemplar esta otra parte de los ensayos. La efectividad del trabajo de mesa suele medirse por sus resultados en la puesta en pie, cuando los actores encarnan los personajes, se mueven por lo que vendría a ser el decorado y marcan movimientos y situaciones. Volviendo a Lumet, este director, tras tres días de trabajo de mesa, iniciaba lo que él llamaba la "marcación". Perimetraba en el suelo con cinta adhesiva cada uno de los decorados interiores en sus dimensiones reales, colocaba los muebles y objetos de la escena y ensayaba en el orden del guion, no de localizaciones, como luego se hace en el rodaje, para que los actores, entre otras cosas, asimilasen el arco de transformación de sus personajes.

Incluso hay casos en que el director usa la puesta en pie con los actores para llegar al logos, a la palabra dicha, a la única parte del guion que pasa a la pantalla casi tal cual, es decir, a los diálogos definitivos. Leo McCarey, por ejemplo, comentaba a los actores la escena, los actores improvisaban y la script iba anotando las frases. En Malas calles (Mean Streets, 1973), Martin Scorsese ensayó durante diez días y el guion se cambió a partir de las improvisaciones grabadas en dichos ensayos. De hecho, este era el procedimiento habitual de Éric Rohmer. Rohmer, en efecto, ha sido uno de los cineastas más involucrados en el proceso de escritura del guion. Incluso tenía perfectamente maquetada la página en su máquina de escribir, de forma que las palabras que entraban en cada página venían luego a ser un minuto 
y medio de imagen. Es decir, la paginación le permitía controlar el ritmo del futuro filme. Luego hacía su peculiar trabajo de mesa: entregaba el guion a los actores para que lo memorizasen, mantenía largas conversaciones con ellos, profundizando en los personajes a partir de sus experiencias personales, y hasta les grababa en un magnetófono o en vídeo. A continuación reescribía los diálogos sin cambiar el contenido, pero sí adaptándolos en su forma al actor/personaje, incorporando giros, matices, expresiones personales. Durante el rodaje, exigía que estos diálogos se repitiesen milimétricamente (Santamaría y Heredero, 2011, pp. 51, 60 y 63).

Es más, si una lectura dramatizada de un guion puede ser un "espectáculo" de la palabra (un acto comunicativo público que reúne a actores y espectadores en una sala), en ciertos casos, la puesta en pie también puede ser el espectáculo. Es decir, hay películas donde ensayo y rodaje se confunden, algo así como L'Impromptu de Versailles (Moliere, 1663), el "action painting" o un concierto de jazz. Son películas nacidas rodando la improvisación de los actores, como Shadows (John Cassavetes, 1961), El rayo verde (Le rayon vert, Éric Rohmer, 1986), Fuyu no kemono / Love Addiction (Nobuteru Uchida, 2010) y Une histoire américaine (Armel Hostiou, 2015). En estos casos, la película es la puesta en pie. El director entiende que lo vivido a partir de una situación improvisada es más "verdad" que el texto escrito por el autor en su torre de marfil y luego diseccionado en torno a una mesa. Pero lo cierto es que estos filmes son rarezas, películas que exploran los límites expresivos, provocaciones que sacan a la luz las contradicciones de los procesos de trabajo que tratan de armonizar la productividad de la industria y la creatividad del arte.

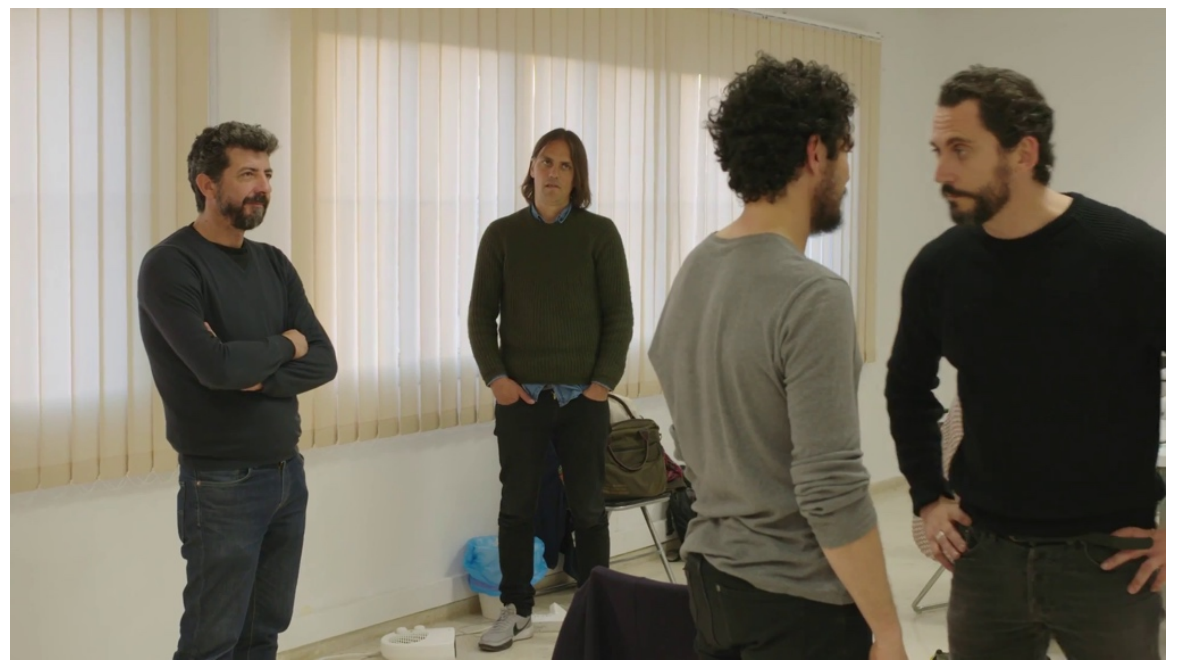

Video 4. La puesta en píe en La peste (Movistar, 2018) https://www.youtube.com/watch?v=t2VibkoEotY\&feature=youtu.be (C) You Tube 
Lo importante para nuestra hipótesis es que la puesta en pie pivota sobre otra clase de inteligencia: la praxis, el hacer, la cinestesia, el movimiento humano, la "lógica" sensorial. Consiste en descifrar lo que el profesional percibe al "levantar" el texto, pues el cuerpo descubre porque siente y tiene memoria; al moverse, analiza, averigua y resuelve. Es más, el cuerpo sutil activa una lógica del sentir de gran capacidad creadora, imaginativa y simbólica por cuanto da entrada a lo inconsciente, a los lugares oscuros del saber. En la puesta en pie, las palabras del guion (logos 1) se someten a la experiencia y la intuición, en lugar de al raciocinio (logos 2), en la búsqueda de una transducción con sentido (logos 3). De hecho, el descubrir haciendo es una técnica que mejora la capacidad de expresión en la mayoría de las artes. En el caso del actor, es fundamental el saber experiencial del cuerpo, por cuanto se comunica con él (el cuerpo es signo), y el habla tiene que ser encarnada, esto es, el diálogo ha de mover a la acción, ha de transformase en actos de habla (Austin, 1982).

\section{Conclusiones}

Hemos visto que, pese a la introducción de los ordenadores, las aplicaciones y la digitalización en el rodaje de películas y series, el audiovisual conserva algo que todavía es casi artesanal: no ha podido desprenderse de la palabra escrita, del guion, del papel, de leer. Es más, si se estudia el proceso creativo de una película, y más en concreto los ensayos, la primera conclusión a la que llegamos es que el guion se somete a un proceso hermenéutico de lectura a la altura de trabajos intelectuales propios de teólogos, juristas y literatos. El trabajo de mesa es el lugar del logos: de la lectura de la palabra (logos 1), de la palabra meditada, argumentada, hablada, razonada (logos 2) y de la palabra que construye pensamiento y sentido (logos 3$)$.

El problema es que cualquier intento de organización productiva del trabajo creativo, y el trabajo de mesa lo es, encaja mal entre unos profesionales que basan su arte en la imaginación, la subjetividad y hasta la improvisación. Por eso, la segunda conclusión es que, aunque el trabajo de mesa es un proceso efectivo, está lleno de dudas: en qué momento situarlo, cuánto debe durar, en qué debe consistir o qué pasa con los casos especiales.

En tercer lugar, su efectividad solo puede medirse teniendo en cuenta no tanto el resultado final de la película o serie como la siguiente fase del ensayo, la puesta en pie, pues hay que acceder a las palabras del guion tanto desde la razón como desde el cuerpo. Se detecta, en este sentido, una controversia en la profesión sobre la dialéctica entre el trabajo de mesa y la puesta en pie. A cada uno de estos 
procesos hemos visto que se le atribuyen unas cualidades. Para la mayoría de los profesionales son complementarias (de ahí que recurran a los dos procesos), pero para algunos son casi excluyentes, de modo que abren un debate del tipo: ¿Desde las palabras del guion $(\log o s$ ), es el estudio o el estímulo, la erudición o la intuición, lo consciente o lo inconsciente, el pensar o el hacer, la razón (logos 2) o la praxis lo que permite encontrar durante los ensayos el sentido que dé forma y contenido a la transducción al lenguaje audiovisual (logos 3)? En otras palabras, y esta es la tercera conclusión, en el proceso hermenéutico que supone un ensayo, hay una complicada interacción entre trabajo de mesa y puesta en pie, entre logos y praxis.

Ahora bien, este debate es un tanto falso si asumimos que no hay disyuntiva, que estamos en un arte industrial, y en consecuencia, el problema es cómo articular la conjunción. De hecho, el ser humano, y sobre todo el artista, no funciona en compartimentos estancos. No es cierto que el trabajo de mesa opere solo sobre la mente y la puesta en pie solo sobre el cuerpo. El trabajo de mesa, y esta es la última conclusión, es una praxis en la que la palabra/logos toma cuerpo y la puesta en pie es una lógica en la que el movimiento/praxis toma la palabra. María Zambrano habla en este sentido de una armonía de contrarios que llama razón poética. Esta es una forma de lógica que ensancha los estrechos márgenes de la delimitación conceptual mediante una síntesis de método y hallazgo, de estudio y delirio, de sabiduría y vacío, de lo apolíneo y lo dionisiaco. Es un saber que acepta la existencia del inferos (allí donde habitan los sentimientos, las pasiones, lo irracional, lo inconsciente, el fondo oscuro) y, por ello, el artista puede llegar al claro del bosque, a algo nuevo, a una transducción de la palabra que huya de lo determinado, prefigurado y consabido.

\section{Referencias bibliográficas}

Angulo, J. y Rebordinos, J. L. (2005). Contra la certeza. El cine de Julio Medem. Huesca: Festival de Huesca.

Austin, J. L. (1982). Cómo hacer cosas con palabras. Barcelona: Paidós.

Barr, T. (2002). Actuando para la cámara. Madrid: Plot.

Ciment, M. (2003). Pequeño planeta cinematográfico. Madrid: Akal.

Chiarini, P. (1993). Introducción. En G. E. Lessing, Dramaturgia de Hamburgo (pp. 11-71). Madrid: ADE.

Dolezel, L. (1986). Semiotics of Literary Communication. Strumenti Critici, 1 (1), 5-48.

Eco, U. (1999). Obra abierta. Barcelona. Ariel.

Edgar-Hunt, R. (2015). Bases del cine: Dirección. Barcelona: Paramon. 
Felmand, S. (2015). El director de cine. Barcelona: Gedisa.

Jacoste Quesada, J. G. (1996). El productor cinematográfico. Madrid: Síntesis.

Knebel, Maria Ossipovna (2013). El último Stanislavsky. Madrid: Fundamentos.

Lowenstein, S. (ed) (2001). Mi primera película. Barcelona: Alba.

Lumet, S. (1999). Así se hace películas. Madrid: Rialp.

Miralles, A. (2000). La direción de actores en el cine. Madrid: Cátedra.

Renoir, J. (1968). La dirección de actores. Disponible en: https://www.youtube.com/watch?v=JGp2b-tfp24

Renoir, J. (2011). Mi vida en el cine. Madrid: Akal.

Rosado, J. C. (27-9-2010). Alicia Hermida: «La inseguridad de los actores es positiva». $E l$ periódico. Disponible https://www.elperiodico.com/es/tele/20100927/alicia-hermida-lainseguridad-de-los-actores-es-positiva-500573

Santamaría, A. y Heredero, C. F. (2011). Eric Rohmer. Madrid: Cátedra.

Zambrano, M. (1986). Claros de bosque. Barcelona: Seix Barral.

\section{Profesionales entrevistados}

Arbeláez, Carlos César (11-8-2017). Director de cine y guionista, Premio al Mejor Nuevo Director del Festival de Cine de San Sebastián por Los colores de la montaña (2010).

Bardem, Miguel (11-10-2017). Guionista y director, entre sus trabajos está la miniserie Prim, el asesinato de la calle del Turco (TVE, 2014).

Calparsoro López-Tapia, Carla (14-12-2016). Actriz y coach, profesora en la Universidad Camilo José Cela.

Collado, Puerto (3-10-2017). Directora artística y decoradora en producciones de cine y televisión, profesora en la UCM.

Cordero, Sebastián (22-6-2018). Director de cine. Nominado a los Premios Platino 2017 en la categoría Mejor dirección de Montaje por su película Sin muertos no hay carnaval (2016).

del Moral, Ignacio (12-1-2017). Autor teatral, guionista de cine y televisión, Premio al Mejor Guion del Círculo de Escritores Cinematográficos por Los lunes al sol (Fernando León de Aranoa, 2002).

Fadón, Javier (8-1-2017). Actor, profesor en la UCJC.

Fernández, Verónica (18-12-2016). Escritora, guionista de cine y televisión, premio Goya por El Bola (Achero Mañas, 2000).

García de Leaniz Caprile, Santiago (13-12-2016). Productor, director de cine, guionista, fotógrafo, miembro de la Academia de Cine Europeo y profesor en la UCJC.

Iglesias, Gervasio (13-9-2017). Productor de cine, entre sus películas se encuentra La isla mínima (Alberto Rodríguez, 2014). 
Manrique, Elena (5-2-2017). Productora de, entre otras, El laberinto del fauno (Guillermo del Toro, 2001) y El orfanato (Juan Antonio Bayona, 2007), profesora en la UCJC.

Querejeta, Gracia (21-2-2017). Cineasta, directora de 15 años y un día (2013), Biznaga de Oro a la Mejor Película en el Festival de Málaga.

Santesmases, Miguel (13-12-2016). Director de cine, su última película es Madrid, above The Moon (2016), fotógrafo, profesor en la UC3M y la UCJC.

Tamayo, Juan Pablo (7-8-2017). Productor cinematográfico de, entre otras, las películas Operación E (Miguel Courtois, 2012) y Eso que llaman amor (Carlos César Arbeláez, 2016).

Urbizu, Enrique (12-9-2017). Guionista y director, Premio Goya a la dirección y guion por No habrá paz para los malvados (2011) 